\title{
PENINGKATAN KOMPETENSI MERANCANG WEB DENGAN MENGGUNAKAN PEMBELAJARAN BERBASIS PROYEK
}

\author{
Oleh : Chandra Anugrah Putra, M.I.kom*
}

\begin{abstract}
ABSTRAK
Penelitian ini menggunakan metode penelitian tindakan (action research). Penelitian ini bertujuan untuk mengetahui penerapan pembelajarand engan menggunakan pembelajaran berbasis proyek dalam kompetensi merancang web mahasiswa. Pada pembelajaran berbasis proyek programming language, mahasiswa akan dapat menganalisis, bereksperimen, serta menciptakan atau merancang sebuah web yang baik, dan tentu akan dapat melayani apa pun permintaan pelanggan yang ingin memesan proyek web dalam dunia pekerjaan. Mahasiswa juga akan menjadi lulusan yang berkualitas apabila terlibat dalam perusahaan yang bergerak dalam bidang web (web developer), karena mereka akan dapat melayani permintaan permbuatan web dengan sangat baik dari pelanggan (client) yang sangat beraneka ragam . Hasil penelitian menunjukkan bahwa: (1) pemahaman HTML mahasiswa dari base line awal sebesar 38\%,ke siklus 3 sebesar 84\%; (2) Analisis proyek mahasiswa dari base line awal sebesar $18 \%$, ke siklus 3 sebesar 78\%;(3) perancangan web mahasiswa dari base line awal sebesar $31 \%$, ke siklus 3 sebesar $80 \%$.
\end{abstract}

Kata kunci: Web, Pembelajaran berbasis proyek, Programming Language.

\section{PENDAHULUAN}

Teknologi telah merambat ke berbagai ranah, baik ranah sosial, politik, informasi, pendidikan, dan lain sebagainya. Web atau yang biasa dikenal dengan nama website, kita dapat senantiasa berbagi informasi, baik itu informasi teks, gambar, video, dan lain sebagainya.

Pembelajar (dosen) maupun lembaga pendidikan kepada para mahasiswa dibidang komputer atau informatika, yang berdampak pada kompetensi akhir mahasiswa yang tidak diharapkan dan tidak sesuai dengan tujuan pembelajaran mata kuliah pemrograman web. Teknologi informasi yang terus berkembang menjadi sesuatu yang juga harus dipelajari oleh para mahasiswa baik di masyarakat, terlebih kalangan mahasiswa dalam bidang komputer atau informatika.

Pada kenyataan yang terjadi dalam praktek pembelajaran yang diterapkan oleh para pembelajar maupun lembaga pendidikan adalah dengan memberikan strategi pembelajaran berbasis proyek perancangan pemrograman web yang 
praktis dan otomatis dibandingkan strategi pembelajaran berbasis proyek perancangan dasar dari pemrograman web tersebut.

Dampak negatif juga terjadi pada lulusan yang akan mengambil matakuliah lanjutan dari pemrograman web ini, yaitu Pemrograman Web Lanjut (PHP\&MySQL). Pemrograman PHP inibertujuan untuk membuat sebuah web yang bersifat dinamis dan terdistribusi ke dalam sebuah database, sudah tentu pemrograman ini membutuhkan strategi pembelajaran berbasis proyek perancangan yang mendasar untuk mendukung sebuah desain maupun dalam penyisipan instruksi-instruksi khusus pada perancangan sebuah web.

Bagaimana mahasiswa mampu mengikuti matakuliah pemrograman web lanjutan tersebut jika mereka sama sekali tidak memahami dasar atau kode $H T M L$ yang seharusnya sudah diterapkan dalam matakuliah sebelumnya, yaitu pemrograman web.

Pada kenyataan dalam proses perkuliahan yang terjadi, ketika dosen menginstruksikan untuk membuat kerangka web, mereka justru menggunakan strategi pembelajaran berbasis proyek perancangan web yang sangat praktis dan otomatis (dalam hal ini menggunakan Dreamweaver atau Joomla).
Pengamatan peneliti pada matakuliah pemrograman web, seringkali dosen memberikan mahasiswa strategi pembelajaran berbasis proyek perancangan web yang praktis dan otomatis, sehingga mahasiswa tidak perlu lagi memahami dan menguasai kodekode pemrograman web dasar seperti Hypertext Markup Language (HTML). Seharusnya, dalam matak uliah pemrograman web tersebut mahasiswa akan mempelajari kode pemrograman $H T M L$, di mana dalam kode HTML mereka juga akan mempelajari komponen dasar seperti tag dan atribut HTML. Pada tag $H T M L$, mahasiswa akan mengetahui bagaimana membuat kerangka web secara mendasar, contohnya seperti start HTML, head, body, end HTML.

Atribut HTML merupakan komponen selanjutnya yang harus dipahami oleh mahasiswa dalam merancang web, dengan atribut tersebut mereka akan melengkapi fungsi tag yang sebelumnya dibahas menjadi lebih hidup. Pada saat dosen mempertanyakan alasan mereka mempergunakan strategi pembelajaran berbasis proyek perancangan praktis dan otomatis tersebut, para mahasiswa menjawab bahwa mereka sudah terbiasa menerapkan strategi pembelajaran berbasis proyek perancangan tersebut pada matakuliah pemrograman web sebelumnya. 
Selanjutnya, ketika dosen meminta mahasiswa merubah desain kerangka web yang telah mereka rancang tadi, hampir secara keseluruhan tidak ada yang dapat merubah sedikitpun kerangka web yang sudah mereka rancang dengan strategi pembelajaran berbasis proyek perancangan praktis dan otomatis tersebut.

Hal inilah yang menjadikan kualitas lulusan sangat rendah dalam kompetensi merancang web, kualitas lulusan akan sangat berkaitan dengan lapangan pekerjaan atau web developer yang akan menggunakan kompetensi lulusan tersebut, bagaimana pun jugaperusahaanperusahaan yang bergerak dalam bidang pengembangan web (web developer), akan sangat membutuhkan keahlian programmer web untuk melayani berbagai macam permintaan pelanggan yang sangat beraneka ragam.

Peneliti telah melakukan pengamatan kompetensi mahasiswa melalui rekaman video pada salah satu sekolah tinggi dalam bidang komputer, peneliti juga melakukan wawancara kepada mahasiswa yang telah menyelesaikan matakuliah Pemrograman Web agar mendapat informasi yang mendukung penelitian ini, peneliti melakukan ini agar memberikan gambaran yang jelas dan bukti empirik yang terjadi di lapangan.

Berdasarkan pengamatan dan hasil wawancara tersebut, peneliti menemukan data empirik yaitu mahasiswa lulusan matakuliah pemrograman web di dalam kelas itu tidak dapat menyelesaikan desain kerangka web yang telah peneliti gambar di papan tulis (whiteboard).

Selain itu, hasil wawancara yang peneliti lakukan terhadap mahasiswa tersebut memberikan komentar bahwa dengan menggunakan strategi pembelajaran berbasis proyek perancangan yang praktis dan otomatis, mereka akan dimudahkan dalam mendesain kerangka web seperti mengatur tata letak, logo, dan membuat mereka menjadi cepat dalam menyusun kerangka web.

Mereka juga mengatakan bahwa dengan menggunakan strategi pembelajaran berbasis proyek perancangan yang praktis dan otomatis, mereka tidak mengenal koding (kode program) dari perancangan web, namun teknik ini memberikan kemudahan dan kecepatan dalam pengaturan (setting) desain sebuah web. Pembelajaran tersebut terus berlanjut sampai pada komponen atau fungsi lain yang dapat mendukung mahasiswa berkompeten dalam merancang sebuah web yang bersifat statis serta belum terdistribusi ke dalam sebuah database, dan tentu saja dengan harapan komponen serta fungsifungsi tadi dikuasai dengan sangat baik oleh mahasiswa dengan menerapkan strategi pembelajaran 
berbasis proyek perancangan programming language.

Pada kenyataannya di dalam proses perkuliahan, mahasiswa justru diminta oleh dosen atau lembaga pendidikan yang menyelenggarakan matakuliah pemrograman web menerapkan strategi pembelajaran berbasis proyek perancangan yang praktis dan otomatis seperti Macromedia Dreamweaver, Drupal, Frontpage, dan sebagainya.

Mereka juga seringkali menggunakan yang lebih praktis lagi menggunakan database yang sudah tersedia seperti Joomla, Wordpress, Moodle, Blogger, dan lain sebagainya. Pada kompetensi inti mata kuliah pemrograman web, mahasiswa diharapkan akan dapat membuat atau merancang sebuah web yang bersifat statis secara programming language. Sebelumnya mahasiswa ini telah menyelesaikan matakuliah algoritma dan pemrograman, serta internet yang merupakan kompetensi dasar yang telah dimiliki mahasiswa dalam mengikuti matakuliah pemrograman web.

Peneliti berpendapat, bahwa indikator kompetensi dapat dikatakan tercapai apabila mahasiswa dalam matakuliah ini dapat menjelaskan dan menerapkan komponenkomponen HTML seperti tag, atribut, css, javascript, dan lain-lain. Mahasiswa dapat dikatakan berkompeten apabila dapat merancang atau membuat sebuah halaman web secara programming language, dan hal ini juga akan berpengaruh kepada mahasiswa yang akan mengikuti matakuliah lanjutan dari pemrograman web.

Peneliti juga telah melakukan pengamatan pada perusahaan pengembangan web (web developer) melalui rekaman video pada salah satu web developer yang berada di Jakarta dan Banjarmasin, peneliti melakukan wawancara kepada pimpinan dan progamer di salah satu perusahaan web developer tersebut terkait informasi yang dapat mendukung penelitian ini, peneliti melakukan ini agar memberikan gambaran yang jelas dan bukti empirik yang terjadi di lapangan.

Berdasarkan pengamatan dan hasil wawancara di dua perusahaan web developer tersebut, peneliti menemukan data empirik yaitu perusahaan pengembangan web (web developer) memang sangat membutuhkan keahlian seorang programer web yang memiliki keahlian mengenal koding atau kode pemrograman web dengan baik, dalam hal ini mereka mampu menerapkan strategi pembelajaran berbasis proyek perancangan web berbasis bahasa pemrograman.

Selain itu hasil wawancara yang peneliti lakukan terhadap pimpinan di dua perusahaan tersebut, memberikan pernyataan yang sama bahwa seorang programer web wajib memahami dan menguasai kode pemrograman web dengan baik, hal 
ini berlaku untuk posisi programer web dan desainer web, sehingga mereka dapat memberikan pelayanan yang terbaik bagi pelanggan atau client dalam pemesanan proyek web.

Penelitian ini bertujuan untuk mengetahui apakah pembelajaran berbasis proyekberpengaruh pada peningkatan kompetensi merancang web. Pembelajaran berbasis proyek dengan menggunakan perancangan programming language diharapkan mampu meningkatkan kompetensi mahasiswa dalam proses perancangan web yang sesuai dengan spesifikasi yang diinginkan.

Evers, Rush dan Iris (1998: 6) mengatakan bahwa:

... competence form a model of general skills that college graduate need to develop to be able to thrive in workplace and serve as foundation for lifelong learning. the skills encompassed in the model are fundamental to developing more specialized skills, and they are generic to all academic specialties.

Mereka mengatakan bahwa kompetensi membentuk model keterampilan umum kepada lulusan perguruan tinggi untuk dapat berkembang di tempat kerja dan berfungsi sebagai dasar untuk belajar sepanjang hayat. Keterampilan yang tercakup dalam model tersebut sangat penting untuk mengembangkan keterampilan yang lebih khusus, dan umumnya mereka untuk semua spesialisasi akademik.
Keterampilan, merupakan komponen yang peneliti pilih berdasarkan kawasan psikomotor seperti diungkapkan oleh Tomei (2005: 57-58) yang menjelaskan tentang klasifikasi dari kawasan psikomotorik terdiri dari imitation, manipulation, precision, articulation, dan naturalization.

Manipulation pada salah satu komponen pada kawasan psikomotor dapat meningkatkan kemampuan untuk melakukan aktivitas kinestetik agar menjadi lebih mudah, tepat, cara yang harmonis dengan keadaan yang terus berubah di luar tingkat perkembangan psikomotor.

Kawasan psikomotor ini akan mendukung mahasiswa untuk mampu menerapkan, mengoperasikan, menggunakan, melakukan atau mengeksekusi suatu proses perancangan web. Sikap, merupakan komponen yang peneliti pilih berdasarkan kawasan afektif seperti diungkapkan oleh Tomei (2005: 53-54) yang menjelaskan tentang klasifikasi dari kawasan afektif terdiri dari receiving, responding, valuing, organizing, dan characterizing. Responding pada salah satu komponen pada kawasan afektif menuntut kepada tingkat penerimaan, kemauan, dan apresiasi dari seseorang.

Kawasan afektif ini akan
mendukung mahasiswa untuk
mampu memberikan respon,
kemauan, berdiskusi, berpatisipasi 
dalam suatu proses perancangan web.Peneliti lebih cenderung menggunakan teori yang dikemukakan oleh Tomei, karena taxonomy dari kawasan sikap dan psikomotor berdasarkan penjelasan teori tersebut sangat relevan dengan konteks penelitian ini yaitu tentang teknologi, dalam hal ini adalah teknologi web.

Oliver

(1996:

mengemukakan World Wide Web atau web sebagai berikut:The World Wide Web is a convention for linking together text documents, images and interactive program over the internet.

Ia mengatakan World Wide Web adalah suatu sarana untuk menghubungkan secara bersamasama dokumen teks, gambar dan program interaktif melalui Internet. Laudon dan Laudon (2010: 51-52) menjelaskan tentang web sebagai berikut:

The World Wide Web is a service provided by the internet that uses universally accepted standards for storing, retrieving, formatting, and displaying information in a page format on the internet.

Mereka menjelaskan bahwa World Wide Web adalah layanan yang disediakan oleh internet menggunakan standar yang diterima secara universal untuk menyimpan, mengambil, memformat, dan menampilkan informasi dalam format halaman di internet. Mereka juga menambahkan halaman web berisi teks, grafik, animasi, suara, dan video yang terhubung ke halaman web lain.

Lever dan McDonald (2011:174) mengatakan fitur ini mengizinkan pengguna (user) untuk memperlihatkan tampilan awal sebuah dokumen dan melihat fungsi yang akan digunakan persis dengan apa yang akan dilihat sebelum itu ditampilkan atau dicetak.

NYC Department of Education (2013:15) memberikan penjelasan umum tentang pembelajaran berbasis proyek, mereka mengatakan pembelajaran berbasis proyek adalah strategi pembelajaran yang memberdayakan peserta didik untuk mengejar pengetahuan konten mereka sendiri dan menunjukkan pemahaman baru melalui berbagai gaya presentasi. http://schools.nyc.gov/documents/tea chandlearn/project_basedFinal.pdf

Peserta didik dapat memanfaatkan pembelajaran berbasis proyek untuk dapat mengoptimalkan pengetahuan mereka masing-masing serta menunjukkan hal-hal baru melalui berbagai macam gaya presentasi.

Blumenfeld, Soloway, Marx, Krajcik, Guzdial, dan Palincsar (2013:24) mengemukakan bahwa proyek memiliki potensi untuk meningkatkan pemahaman yang mendalam karena siswa perlu untuk memperoleh dan menerapkan informasi, konsep, dan prinsipprinsip, dan mereka memiliki potensi 
untuk meningkatkan kompetensi dalam berpikir (belajar dan metakognisi) karena siswa perlu merumuskan rencana, melacak kemajuan, dan solusi evaluasi. http://mathforum.org/wikis/uploads/ Blumenfeld.motivating.project.based .pdf

Pendapat lain yang juga relevan dengan penjelasan di atas dikemukakan oleh Patton dan Robin (2014:54) yang mengatakan bahwa pembelajaran berbasis proyek mengacu pada siswa dalam merancang, merencanakan, dan melaksanakan proyek diperpanjang yang menghasilkan output untuk dipamerkan kepada publik seperti produk, publikasi, atau presentasi.

Pendapat di atas sama dengan yang dikemukakan oleh Brookshear (2013:254) mengemukakan bahasa pemrograman sebagai berikut:

...programming language similar to our pseudocode have been developed that allow algorithms to be expressed in a form that is both palatable to human and easily convertible into machine language instrctions.

Ia mengatakan bahwa bahasa pemrograman serupa dengan pseudocode yang telah dikembangkan dan memungkinkan algoritma diekspresikan di suatu format yang keduanya dapat diterapkan oleh manusia dan dengan mudah dapat dirubah ke dalam bentuk perintah atau instruksi bahasa mesin.
Peneliti menemukan kelemahan dan kelebihan dari perancangan web secara pemrograman dari pendapat McLeod dan Schell (2009:403) sebagai berikut:

Kelemahan membuat halaman web dengan editor teks seperti notepad adalah keharusan untuk mempelajari perintah - perintah HTML dan proses pembuatan kode. Meskipun sederhana, pengodean di notepad memakan banyak waktu. Tetapi, ada dua keuntungan membuat kode HTML di notepad: kode yang dibuat efisien dan manajer dapat lebih memahami bagaimana halaman web bekerja. Brooks (2007:1-2) mengatakan sebuah dokumen HTML dasar membutuhkan minimal empat set elemen:

$<\mathrm{html}>\ldots</ \mathrm{html}>$

$\langle$ head $>\ldots</$ head $>$

$\langle$ title $>\ldots</$ title $>$

$<$ body $>$... < body $>$

Unsur-unsur ini menentukan bagian-bagian penting dari dokumen HTML, yaitu: dokumen itu sendiri, bagian judul, dan bagian tubuh. Masing-masing unsur didefinisikan oleh dua tag awal dan tag akhir. Tags selalu tertutup dalam kurung sudut: <..>. Tag akhir dimulai dengan garis miring (/).

Pada penerapan teknik perancangan Programming Language ini, peneliti menggunakan aplikasi Notepad. Menurut Wilson, Miller, Palmer, Rennick, dan Torbert (2011:131) pengertian notepad 
adalah sebagai berikut: Notepad is a basic plain-text editor that you can use to write code without the fuss and worry of text formatting; it doesn't support any special document formatting or characters at all, which is what makes it great for writing code and Web documents.

Penjelasan di atas mengatakan bahwa notepad adalah editor teks dasar yang dapat anda gunakan untuk menulis kode tanpa kesulitan apapun, dan tanpa khawatir apabila format teks tidak mendukung format khusus dari suatu dokumen atau karakter, yang terpenting adalah untuk menuliskan kode dan membuat dokumen Web. Mereka juga menambahkan bahwa notepad merupakan editor teks yang termasuk dalam sebagian besar pengguna Windows karena produk Microsoft tersebut dikemas dalam setiap sistem operasi Windows.

\section{METODE PENELITIAN}

Penelitian ini menggunakan metode penelitian tindakan (action research). Penelitian tindakan merupakan suatu pencarian sistematik yang dilaksanakan oleh para pelaksana program dalam kegiatannya sendiri (dalam pendidikan dilakukan olehguru, dosen, kepala sekolah, konselor), dalam megumpulkan data tentang pelaksanaan kegiatan, keberhasilan dan hambatan yang dihadapi, untuk kemudian menyusun rencana dan melakukan kegiatan-kegiatan penyempurnaan. Penelitian tindakan adalah penelitianyang berorientasi pada penerapan tindakan dengan tujuan peningkatan mutu ataupemecahan masalah pada suatu kelompok subyek yang diteliti dan mengamati tingkatkeberhasilan atau akibat tindakannya, untuk kemudian diberikan tindakan lanjutan yangbersifat penyempurnaan tindakan atau penyesuaian dengan kondisi dan situasi sehinggadiperoleh hasil yang lebih baik.

Tujuan penelitian ini adalah untuk memperbaiki masalah nyata yang terjadi di dalam kelas, sekaligus mencari apakah dengan menggunakan tindakan yang dilakukan dapat memecahkan masalah tersebut. Pada penelitian ini, mahasiwa diharapkan dapat memiliki kompetensi dalam proses perancangan web, hal ini juga akan dapat berpengaruh pada pekerjaan mahasiswa apabila mereka bekerja di bidang web.

Peneliti akan menjelaskan secara khusus langkah-langkah pada pembelajaran berbasis proyek. Berdasarkan hal itu, peneliti akan mengintegrasikannya ke dalam sintaks dari strategi pembelajaran berbasis proyek yang telah ditentukan.

Adapun langkah-langkah tersebut terdiri dari:

- $\quad$ Sets the stage for students with real-life

- A Driving Question 
- Inquiry and Innovation

- Design a plan for a project

- Accumulate the materials

- Create a schedule

- Create their projects

- Present their projects

- Assess the outcome

- Monitor the students and the progress of the project

- Reflect on the process and evaluate the projects

Langkah - langkah di atas dapat dilihat pada Gambar 1.

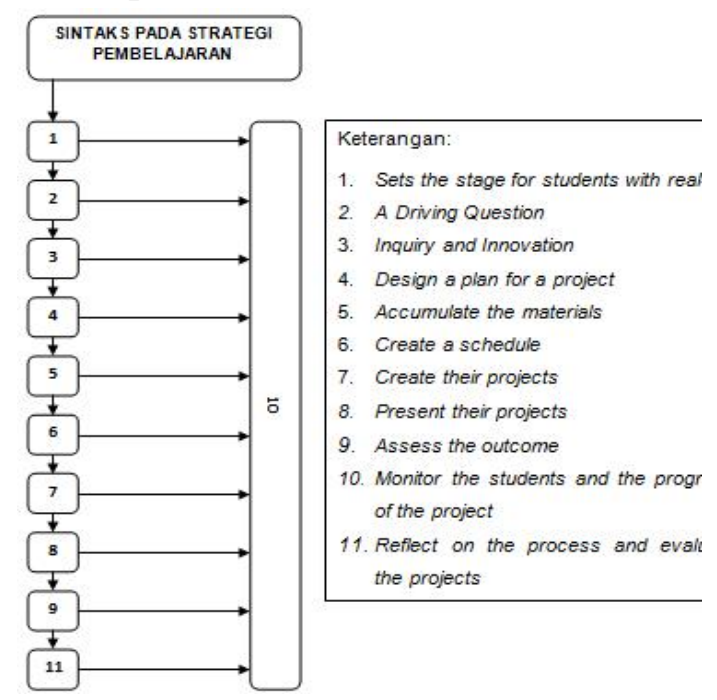

Gambar 1. Sintaks Strategi Pembelajaran Berbasis Proyek

\section{HASIL DAN PEMBAHASAN}

Berdasarkan hasil pengamatan awal (base line), siklus 1 , siklus 2, dan siklus 3 diperoleh data mahasiswa dalam pembelajaran pemrograman web semester IV di STMIK Banjarbaru, dapat dilihat pada tabel dibawah ini.
Tabel 1. Penilaian Aktifitas Mahasiswa

Siklus 1:

\begin{tabular}{|c|c|c|c|c|c|}
\hline \multirow{3}{*}{$\begin{array}{c}\text { No } \\
1 \\
\end{array}$} & \multirow{3}{*}{$\begin{array}{c}\text { Indikator } \\
\text { Pemahaman HTML }\end{array}$} & \multicolumn{4}{|c|}{ Base Lined } \\
\hline & & \multicolumn{2}{|c|}{ Penelitian Awal } & \multicolumn{2}{|c|}{ Siklus 1} \\
\hline & & Jumlah & $\%$ & Jumlah & $\%$ \\
\hline $\mathrm{a}$ & $\begin{array}{c}\text { Mahasiswa } \\
\text { menggunakan } \\
\text { algoritma dalam } \\
\text { menganalisis kode }\end{array}$ & 4 & $27 \%$ & 4 & $27 \%$ \\
\hline $\mathrm{b}$ & $\begin{array}{c}\text { Mahasiswa } \\
\text { menggunakan Tag } \\
\text { HTML }\end{array}$ & 14 & $93 \%$ & 15 & $100 \%$ \\
\hline $\mathrm{c}$ & $\begin{array}{c}\text { Mahasiswa } \\
\text { menggunakan atribut } \\
\text { HTML }\end{array}$ & 3 & $20 \%$ & 6 & $40 \%$ \\
\hline $\mathrm{D}$ & $\begin{array}{c}\text { Mahasiswa } \\
\text { menggunakan css \& } \\
\text { javascript HTML }\end{array}$ & 2 & $13 \%$ & 4 & $27 \%$ \\
\hline \multicolumn{2}{|r|}{ Rata - rata } & & $38 \%$ & & $48 \%$ \\
\hline 2 & Analisis Proyek & Jumlah & $\%$ & Jumlah & $\%$ \\
\hline A & $\begin{array}{c}\text { Mahasiswa menganalisis } \\
\text { kerangka web }\end{array}$ & 2 & $13 \%$ & 6 & $40 \%$ \\
\hline B & $\begin{array}{c}\text { Mahasiswa menganalisis } \\
\text { konten web }\end{array}$ & 4 & $27 \%$ & 6 & $40 \%$ \\
\hline $\mathrm{C}$ & $\begin{array}{c}\text { Mahasiswa menganalisis } \\
\text { template web }\end{array}$ & 2 & $13 \%$ & 4 & $27 \%$ \\
\hline D & $\begin{array}{c}\text { Mahasiswa menganalisis } \\
\text { komponen pendukung } \\
\text { web }\end{array}$ & 3 & $20 \%$ & 6 & $40 \%$ \\
\hline \multicolumn{2}{|r|}{ Rata - rata } & & $18 \%$ & & $37 \%$ \\
\hline 3 & Perancangan Web & Jumlah & $\%$ & Jumlah & $\%$ \\
\hline A & $\begin{array}{l}\text { Mahasiswa merancang } \\
\text { web sesuai kerangka }\end{array}$ & 4 & $27 \%$ & 6 & $40 \%$ \\
\hline B & $\begin{array}{l}\text { Mahasiswa merancang } \\
\text { web sesuai desain }\end{array}$ & 5 & $33 \%$ & 6 & $40 \%$ \\
\hline $\mathrm{C}$ & $\begin{array}{l}\text { Mahasiswa merancang } \\
\text { web sesuai konten }\end{array}$ & 5 & $33 \%$ & 7 & $47 \%$ \\
\hline \multirow{2}{*}{\multicolumn{2}{|c|}{$\frac{\text { Rata - rata }}{\text { Total Rata - rata } A+B+C}$}} & & $31 \%$ & & $42 \%$ \\
\hline & & & $32 \%$ & & $42 \%$ \\
\hline
\end{tabular}

Pada tabel aktifitas siklus 1 di atas, dapat disimpulkan bahwa belum terjadi peningkatan kompetensi merancang web. Masing-masing komponen dan total rata-rata keseluruhan masih di bawah 50\% dari 5 pertemuan yang telah dilaksanakan, sehingga harus dilanjutkan pada siklus 2 . 
Siklus 2:

\begin{tabular}{|c|c|c|c|c|c|}
\hline \multirow{3}{*}{$\begin{array}{c}\text { No } \\
1\end{array}$} & \multirow{3}{*}{$\begin{array}{c}\text { Indikator } \\
\text { Pemahaman HTML }\end{array}$} & \multicolumn{4}{|c|}{ Base Lined } \\
\hline & & \multicolumn{2}{|c|}{ Siklus 1} & \multicolumn{2}{|c|}{ Siklus 2} \\
\hline & & Jumlah & $\%$ & Jumlah & $\%$ \\
\hline $\mathrm{a}$ & $\begin{array}{c}\text { Mahasiswa } \\
\text { menggunakan } \\
\text { algoritma dalam } \\
\text { menganalisis kode }\end{array}$ & 4 & $27 \%$ & 9 & $\begin{array}{l}60 \\
\%\end{array}$ \\
\hline $\mathrm{b}$ & $\begin{array}{c}\text { Mahasiswa } \\
\text { menggunakan Tag } \\
\text { HTML }\end{array}$ & 15 & $100 \%$ & 15 & $\begin{array}{l}10 \\
0 \%\end{array}$ \\
\hline $\mathrm{c}$ & $\begin{array}{c}\text { Mahasiswa } \\
\text { menggunakan atribut } \\
\text { HTML }\end{array}$ & 6 & $40 \%$ & 8 & $\begin{array}{l}53 \\
\%\end{array}$ \\
\hline $\mathrm{D}$ & $\begin{array}{c}\text { Mahasiswa } \\
\text { menggunakan css \& } \\
\text { javascript HTML }\end{array}$ & 4 & $27 \%$ & 6 & $\begin{array}{l}40 \\
\%\end{array}$ \\
\hline & Rata - rata & & $48 \%$ & & $\begin{array}{l}63 \\
\%\end{array}$ \\
\hline 2 & Analisis Proyek & Jumlah & $\%$ & Jumlah & $\%$ \\
\hline A & $\begin{array}{c}\text { Mahasiswa menganalisis } \\
\text { kerangka web }\end{array}$ & 6 & $40 \%$ & 9 & $\begin{array}{l}60 \\
\%\end{array}$ \\
\hline B & $\begin{array}{c}\text { Mahasiswa menganalisis } \\
\text { konten web }\end{array}$ & 6 & $40 \%$ & 9 & $\begin{array}{l}60 \\
\%\end{array}$ \\
\hline $\mathrm{C}$ & $\begin{array}{c}\text { Mahasiswa menganalisis } \\
\text { template web }\end{array}$ & 4 & $27 \%$ & 6 & $\begin{array}{l}40 \\
\%\end{array}$ \\
\hline $\mathrm{D}$ & $\begin{array}{c}\text { Mahasiswa menganalisis } \\
\text { komponen pendukung } \\
\text { web }\end{array}$ & 6 & $40 \%$ & 8 & $\begin{array}{l}53 \\
\%\end{array}$ \\
\hline & Rata - rata & & $37 \%$ & & $\begin{array}{l}53 \\
\%\end{array}$ \\
\hline 3 & Perancangan Web & Jumlah & $\%$ & Jumlah & $\%$ \\
\hline a & $\begin{array}{l}\text { Mahasiswa merancang } \\
\text { web sesuai kerangka }\end{array}$ & 6 & $40 \%$ & 9 & $\begin{array}{l}60 \\
\%\end{array}$ \\
\hline B & $\begin{array}{c}\text { Mahasiswa merancang } \\
\text { web sesuai desain }\end{array}$ & 6 & $40 \%$ & 9 & $\begin{array}{l}60 \\
\%\end{array}$ \\
\hline $\mathrm{C}$ & $\begin{array}{c}\text { Mahasiswa merancang } \\
\text { web sesuai konten }\end{array}$ & 7 & $47 \%$ & 11 & $\begin{array}{l}73 \\
\%\end{array}$ \\
\hline & Rata-rata & & $42 \%$ & & $\begin{array}{l}64 \\
\%\end{array}$ \\
\hline & Rata - rata A + B + C & & $42 \%$ & & $\begin{array}{l}60 \\
\%\end{array}$ \\
\hline
\end{tabular}

Siklus 3:

\begin{tabular}{|c|c|c|c|c|c|}
\hline \multirow{3}{*}{$\begin{array}{c}\text { No } \\
1\end{array}$} & \multirow{3}{*}{$\begin{array}{c}\text { Indikator } \\
\text { Pemahaman } \\
\text { HTML }\end{array}$} & \multicolumn{4}{|c|}{ Base Lined } \\
\hline & & \multicolumn{2}{|c|}{ Siklus 2} & \multicolumn{2}{|c|}{ Siklus 3} \\
\hline & & $\begin{array}{c}\text { Jumla } \\
\text { h }\end{array}$ & $\%$ & Jumlah & $\%$ \\
\hline $\mathrm{a}$ & $\begin{array}{c}\text { Mahasiswa } \\
\text { menggunakan } \\
\text { algoritma dalam } \\
\text { menganalisis kode }\end{array}$ & 9 & $60 \%$ & 12 & $80 \%$ \\
\hline $\mathrm{b}$ & $\begin{array}{c}\text { Mahasiswa } \\
\text { menggunakan Tag } \\
\text { HTML }\end{array}$ & 15 & $100 \%$ & 15 & $100 \%$ \\
\hline c & $\begin{array}{c}\text { Mahasiswa } \\
\text { menggunakan atribut } \\
\text { HTML }\end{array}$ & 8 & $53 \%$ & 12 & $80 \%$ \\
\hline D & $\begin{array}{c}\text { Mahasiswa } \\
\text { menggunakan css \& } \\
\text { javascript HTML }\end{array}$ & 6 & $40 \%$ & 11 & $73 \%$ \\
\hline \multicolumn{2}{|r|}{ Rata - rata } & & $63 \%$ & & $84 \%$ \\
\hline 2 & Analisis Proyek & Jumlah & $\%$ & Jumlah & $\%$ \\
\hline $\mathrm{a}$ & $\begin{array}{c}\text { Mahasiswa } \\
\text { menganalisis } \\
\text { kerangka web }\end{array}$ & 9 & $60 \%$ & 11 & $73 \%$ \\
\hline B & $\begin{array}{c}\text { Mahasiswa } \\
\text { menganalisis konten } \\
\text { web }\end{array}$ & 9 & $60 \%$ & 12 & $80 \%$ \\
\hline $\mathrm{C}$ & $\begin{array}{l}\text { Mahasiswa } \\
\text { menganalisis } \\
\text { template web }\end{array}$ & 6 & $40 \%$ & 11 & $73 \%$ \\
\hline $\mathrm{D}$ & $\begin{array}{l}\text { Mahasiswa } \\
\text { menganalisis } \\
\text { komponen } \\
\text { pendukung web }\end{array}$ & 8 & $53 \%$ & 12 & $80 \%$ \\
\hline \multicolumn{2}{|r|}{ Rata - rata } & & $53 \%$ & & $78 \%$ \\
\hline 3 & Perancangan Web & Jumlah & $\%$ & Jumlah & $\%$ \\
\hline $\mathrm{a}$ & $\begin{array}{c}\text { Mahasiswa } \\
\text { merancang web } \\
\text { sesuai kerangka }\end{array}$ & 9 & $60 \%$ & 12 & $80 \%$ \\
\hline $\mathrm{B}$ & $\begin{array}{c}\text { Mahasiswa } \\
\text { merancang web } \\
\text { sesuai desain }\end{array}$ & 9 & $60 \%$ & 11 & $73 \%$ \\
\hline $\mathrm{C}$ & $\begin{array}{c}\text { Mahasiswa } \\
\text { merancang web } \\
\text { sesuai konten }\end{array}$ & 11 & $73 \%$ & 13 & $87 \%$ \\
\hline \multirow{2}{*}{\multicolumn{2}{|c|}{$\begin{array}{c}\text { Rata - rata } \\
\text { Total Rata - rata } \mathbf{A}+\mathbf{B}+ \\
\text { C }\end{array}$}} & & $64 \%$ & & $80 \%$ \\
\hline & & & $60 \%$ & & $81 \%$ \\
\hline
\end{tabular}

Pada tabel aktifitas siklus 2 di atas, dapat disimpulkan bahwa kompetensi merancang webmahasiswa cukup meningkat. Hanya saja masing-masing komponen dan total rata-rata keseluruhan belum cukup untuk mencapai komptensi yang diharapkan, rata-rata tersebut masih mencapai kisaran $60 \%$ dari 5 pertemuan yang telah dilaksanakan, sehingga memang harus dilanjutkan pada siklus 3 .

Pada tabel aktifitas siklus 3 di atas, dapat disimpulkan bahwa sudah terjadi peningkatan kompetensi merancang web. Masing-masing komponen dan total rata-rata keseluruhan telah mencapai komptensi yang diharapkan, rata-rata tersebut mencapai $80 \%$ dari 4 
pertemuan yang telah dilaksanakan, sehingga kompetensi merancang web mahasiswa meningkat pada siklus 3, nilai rata-rata keseluruhan menunjukkan telah mencapai kompetensi yang diharapkan dalam proses perancangan web. Berdasarkan hasil pada tabel di atas dapat disimpulkanbahwa pemahaman HTML mahasiswa dari base line awal sebesar $38 \%$, dan sampai pada siklus 3 sebesar 84\%. Analisis proyek mahasiswa dari base line awal sebesar $18 \%$, dan sampai pada siklus 3 sebesar 78\%.Perancangan web mahasiswa dari base line awal sebesar $31 \%$, dan sampai pada siklus 3 sebesar $80 \%$.

Penelitian ini melibatkan peneliti sendiri, praktisi, dan dosen yang telah melaksanakan proses pembelajaran berdasarkan strategi pembelajaran pada mata kuliah pemrograman web. Laboratorium yang digunakan sudah terfasilitasi dengan baik dari perangkat keras seperti komputer yang sesuai dengan spesifikasi, sehingga sangat mendukung praktikum dalam proses perancangan web, kemudian sistem operasi dan aplikasi yang digunakan mahasiswa dalam proses perancangan web juga dapat digunakan dengan baik dan lancar.

Programming language memiliki keuntungan bagi seseorang dalam merancang sebuah program. Peneliti menemukan pendapat yang relevan dengan hal tersebut, Capron dan Johnson

(2004:444) mengemukakan dengan memahami bahasa pemrograman, seorang pemrogram (programmer) dapat menjadi solusi untuk memecahkan masalah. Mereka mengatakan:

...the programmer prepares the instructions that make up a program, runs the instructions on the computer to see whether they produce the correct result, makes any necessary corrections, and then writes a report on the program.

Penjelasan di atas mengatakan bahwa programmer mempersiapkan instruksi pembuatan suatu program, menjalankan instruksi tersebut pada komputer untuk melihat apakah mereka menghasilkan hasil benar, perlu koreksi dalam pembuatan program, kemudian menuliskan suatu laporan pada program.

Rainer dan Cegielski memberikan pendapat yang sama tentang bahasa pemrograman atau programming language sebagai berikut:

Programming language allow people to write instructions that tell computers what to do. They are the means by which all systems and application software are developed.

Penjelasan di atas mengatakan bahwa bahasa pemrograman memungkinkan orang untuk menulis instruksi yang memberitahu komputer apa yang harus dilakukan. Mereka adalah sarana dari semua sistem dan aplikasi perangkat lunak yang telah dikembangkan. Rainer dan Cegielski juga menambahkan, 
karena komputer melakukan apa yang mereka beritahukan, bahasa pemrograman memerlukan tingkat presisi yang tinggi dan kelengkapan.

$$
\text { Selanjutnya Marakas }
$$

memberikan pendapat tentang bahasa pemrograman sebagai berikut:

...programming language allows a programmer to develop the sets of instructions that constitute a computer program. Many different programming language have been developed, each with its own unique vocabulary, grammar, and uses. Ia mengatakan bahwa bahasa pemrograman memungkinkan programmer untuk mengembangkan satu set instruksi yang membentuk sebuah program komputer. Banyak bahasa pemrograman yang berbeda telah dikembangkan, masing-masing dengan kosakata yang unik, tata bahasa, dan penggunaannya.

Strategi pembelajaran berbasis proyek perancangan programming language merupakan teknik perancangan yang dapat digunakan mahasiswa dalam memberikan seperangkat kode atau perintah yang diinstruksikan kepada komputer untuk menghasilkan suatu bentuk hasil program yang diinginkan. Selain itu dengan memahami dan menguasai teknik ini, mahasiswa akan dapat mengolah instruksi dengan kode, memperbaiki program, membuat program, menganalisis dan memecahkan berbagai macam masalah yang terjadi pada kesalahan program (error systems) dengan baik.

\section{KESIMPULAN}

Berdasarkan hasil penelitian, analisis data, dan pembahasan hasil penelitian tentang pengaruh strategi pembelajaranberbasis proyek perancangan terhadap kompetensi merancang web. dapat diberikan kesimpulan sebagai berikut:

Pemahaman HTML mahasiswa dari base line awal sebesar 38\%, dan sampai pada siklus 3 sebesar $84 \%$. Analisis proyek mahasiswa dari base line awal sebesar $18 \%$, dan sampai pada siklus 3 sebesar $78 \%$. Perancangan web mahasiswa dari base line awal sebesar $31 \%$, dan sampai pada siklus 3 sebesar $80 \%$. Penggunaan strategi pembelajaran berbasis proyek perancangan programming language membuat mahasiswa merancang web dengan cara memahami dengan baik kodekode pemrograman seperti tag dan atribut $H T M L$, dengan strategi pembelajaran berbasis proyek perancangan programming language mereka dapat merancang web sesuai spesifikasi web proyek yang diberikan.

$$
\text { Penggunaan strategi }
$$
pembelajaran berbasis proyek perancangan programming language dapat membuatmahasiswa menginstruksikan kode HTML kepada komputer untuk menghasilkan suatu bentuk hasil program yang dibutuhkan mahasiswa dalam proses perancangan web. 
Dosen

sangat

direkomendasikan menggunakan strategi pembelajaran berbasis proyek perancangan programming language $(P L)$ dalam mata kuliah yang berhubungan dengan perancangan web.

\section{DAFTAR PUSTAKA}

Blumenfeld, Phyllis C. Elliot.S, Ronald W. Marx, Joseph S. Krajcik, Mark Guzdial, dan Annemarie Motivating Palicsar. Doing, Supporting the Learning.http://mathforum.org/ wikis/uploads/Blumenfeld.moti vating.project.based.pdf (diakses 6 April 2015).

Brooks, David R. 2007. An Introduction to HTML and JavaScript: for Scientists and Engineers. Norristown: Springer.

Brookshear , J. Glenn. 2013. Computer Science An Overview, $11^{\text {th }} \quad$ Edition. London: Pearson.

Capron, H.L. dan J.A. Johnson. 2004. Computers: Tools For An Information Age, $8^{\text {th }}$ Edition. New Jersey: Pearson.

Duffy, Judy Lever dan Jean B. McDonald. 2011. Teaching and Learning with Technology. Boston: Pearson.

Evers, Frederick T., James C. Rush dan Iris Berdrow. 1998. The Bases of Competence: Skills For Lifelong Learning and Employability. California: Jossey-Bass Inc.

Laudon, Kenneth C., dan Jane P. Laudon, 2010. Management Information Systems: Managing The Digital Firm. New Jersey: Pearson.
Marakas, O' Brien. 2011. Management Information Systems. New York: McGrawHill.

McLeod, Raymond Jr., dan George P. Schell. 2009. Sistem Informasi Manajemen. Jakarta: Salemba.

NYC Department of Education. Project-Based Learning: Inspiring Middle School Students to Engage in Deep and Active Learning.http://schools.nyc.go v/documents/teachandlearn/pro ject_basedFinal.pdf (diakses 6 April 2015).

Oliver,Dick. 1996. Netscape 2. Indianapolis: Sams.net.

Patton, Alec., dan Jeff Robin. Work That Matters: The Teacher's Guide to Project-Based Learning.http://www.innovatio nunit.org/sites/default/files/Tea cher\%27s\%20Guide\%20to\%20 Project-based\%20Learning.pdf (diakses 6 April 2015).

Rainer, R. Kelly dan Casey G. Cegielski. 2011. Introduction to Information Systems: Enabling and Transforming Business, Third Edition. New Jersey: John Wiley.

Tomei,Lawrence A. 2005. Taxonomy For The Technology Domain. London: Idea Group.

Wilson, Lisa Sabin., Cory Miller, Kevin Palmer, Andrea Rennick, and Michael Torbert. 2011. Wordpress All In One for Dummies. New Jersey: Wiley Publishing. 